\title{
METABOLISM EXPERIMENTS IN ARTIFICIAL NUTRITION, WITH SPECIAL REFERENCE TO THE HYPODERMIC METHOD.
}

\section{HERBERT SWIFT CARTER, M.D.}

NEW YORK.

[From the Pathological Laboratory of the Presbyterian Hospital and the Laboratory of Biological Chemistry of Columbia University, at the College of Physicians and Surgeons.]

The whole subject of artificial nutrition presents great fascination for internists both from the theoretical and the practical point of view; for the idea of nourishing the body, meeting its physiologic needs, so to speak, without the knowledge or consent of the patient, when occasion arises, has seemed an end highly desirable at times.

The conditions under which this would be of value are, of course, various, and need not be discussed here beyond pointing out the fact that in cases of subnutrition which, in part or whole, preclude the natural method of maintaining the physical economy, some such method would often be of the greatest use. Thus, it is indicated in acute gastroenteritis in children, in marasmus, in strictures of the alimentary tract when the patient comes under observation in a condition too weakened to allow of an operation for the time being, etc.

With the introduction of the stomach tube in $18 \% 0$, by Kussmaul, we were enabled to nourish certain cases in which forced feeding is a necessity, despite the existence of a fairly normal digestive tract, as in cases of mental disease. Later, the rectum as an auxiliary stomach came into general use. Attempts were made to give nourishment by means of hypodermic food solution, or by the intraperitoneal route. Of course, any form of artificial feeding, to be entirely sufficient, has to meet the actual needs of metabolism. The requisite amount of nitrogen and heat units must be furnished or the organism will be forced to run at an economic loss, resulting in loss of flesh and strength.

Our knowledge of these requirements has been greatly increased since Voit and his pupils determined the average amount of the different food elements used by individuals doing light or heavy muscular work and maintaining their body weight. According to this standard, a person of average weight (70 to 75 kilos) needs about 118 grams of protein, 56 grams of fat and 500 grams of carbohydrate, with a total fuel value of 3,000 large calories, although Voit $^{1}$ was able to establish nitrogenous

1. Voit: Ztschr. f. Biol., xxv, 261. 
equilibrium for a short time in one patient who took only 8 grams of nitrogen, which corresponds to 48.5 grams of proteid, for a day's ration. This, however, he considered far too small an amount to maintain nitrogen equilibrium for any length of time.

Chittenden ${ }^{2}$ became convinced that a low protein diet could be maintained, not only without detriment to the individual, but to his actual advantage, provided sufficient heat units were furnished by the other food elements. This he proved to his satisfaction in his interesting experiments on athletes, soldiers and students, representing individuals doing, respectively, severe, moderate or light muscular work. He found that the average requirements per kilo of body weight were as follows : 0.12 gram nitrogen, representing 0.65 gram protein per kilo of body weight, with a total fuel value of the food represented by 32 calories per kilo, made up largely of fats and carbohydrates.

This, therefore, can be taken as representing the minimum food requirements necessary to maintain not only the nitrogenous equilibrium, but the general physical condition and body weight of persons who are at work, while at rest the calorific value of the food can be reduced to about 25 calories per kilo. ${ }^{3}$ Any form of alimentation to be complete must meet these requirements, although under pathologic conditions one would be satisfied with something less than the ideal.

With the older standards, the problem seemed out of reach, but with the introduction of these lesser requirements artificial nutrition seems a much more promising field, and it was with this in mind that the following studies were undertaken.

In approaching this subject, two questions naturally present themselves: (1) Is the method ordinarily in use capable of accomplishing satisfactory artificial nutrition? (2) If not, wherein does it fail, and what other methods offer a possible solution of the difficulty?

In rectal feeding, the most common method of artificial nutrition, we have these questions to answer. As to whether this form of feeding is capable of supplying the needs of metabolism, if one regularly weighs these patients daily or even watches them clinically from day to day, the answer must be, No. They do not thrive. This, I think, will be borne out by the clinical experience of most of us. Rectal feeding is, at best, a poor substitute for stomach feeding, although, of course, patients differ, and in some it seems more successful than in others. It must be borne in mind, however, that most people can go without food very

2. Chittenden: Physiologic Economy in Nutrition.

3. Lusk: Jour. Am. Med. Assn., xlix, 201. 
comfortably for a number of days, provided they are supplied with water, but after a certain time, whether on rectal feeding or not, they often seem to retrograde suddenly.

In order to answer the question as to the specific cause of failure in most of these cases, one must study the metabolism and carefully estimate the intake and output, with especial reference to the nitrogen, as the best index of metabolism. The following figures show the results of metabolism in three cases of rectal feeding and may be taken as fairly typical of a large class, as they occurred in one of the large city hospitals, under nursing conditions which are as good as can be found. If these results are true under favorable conditions, what can be expected under ordinary conditions, outside the hospitals?

It can not be said that more satisfactory results may not at times be obtained by rectal feeding. But these cases probably represent the average. In all of them the usual precautions were taken: the colon was cleared daily, the injections were given high up, and the report, in every instance, was that they were "well retained." The entire twenty-fourhour urine, all results of rectal irrigation, and all stools were saved, and, together with a sample of the food, were sent to the laboratory daily. It seemed a work of supererogation to estimate the intake and output of nitrogen, for the results of the cleansing enemata were evidently an almost clear return of the nutrient material, and one could tell by inspection that little, if anything, was being absorbed. The following figures, however, represent the daily nitrogenous balances, estimated by the Kjeldahl method, and show graphically the failure of this method of nutrition; since in these cases at least nitrogenous equilibrium was far from being maintained.

CASE 1.-Gastric Ulcer. Man, aged 46, weight 115 pounds.

History.-Patient had been on rectal feeding three days before the test was begun. The nutrient fluid consisted of peptonized milk and eggs, 1240 c.c. per twenty-four hours, with a total nitrogen value of 11.78 grams.

NITROGENoUs BALANCE. -FIRST DAY.

Total intake of food nitrogen $\ldots \ldots \ldots \ldots \ldots \ldots \ldots \ldots \ldots \ldots$ grams.

Total nitrogen output (urine, 4.74 grams; feces, 23.95

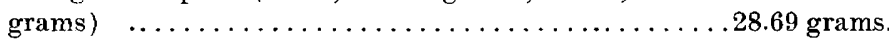

Total loss of nitrogen, 24 hours, output in excess of intake. 16.91 grams.

Total loss in body weight. . . . . . . . .

NITROGENOUS BALANCE.-SECOND DAY.

Total intake of food nitrogen...............

Total nitrogen output (urine, 11.5 grams; feces, -; irri-

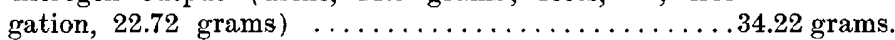

Total loss of nitrogen, 24 hours, output in excess of intake. .21.80 grams.

Total loss in body weight...................... 2 pounds. 
NITROGENOU'S BALANCE.-THIRD DAY.

Food formula changed this day to peptonized milk, glucose and water, 2,000 c.c. in all for the twenty-four hours.

Total intake of food nitrogen................ 7.20 grams.

Total nitrogen output (urine, 9.58 grams; feces, 6.43

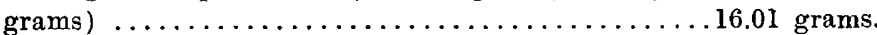

Total loss of nitrogen, 24 hours, output in excess of intake... 8.81 grams.

Total loss in body weight $\ldots \ldots \ldots \ldots \ldots \ldots \ldots \ldots \ldots \ldots . \ldots \ldots$ pounds.

In this balance for the third day we see for the first time that something was actually absorbed by the rectum, or else retained, for the food intake was 7.2 grams nitrogen, and the fecal nitrogen equals 6.43 grams, leaving an absorption balance of +0.67 gram nitrogen, which is, of course, so small as to amount to nothing from the standpoint of nutrition.

(NoTE.-The probable explanation of the fact that on the first two days the nitrogen in the stools and irrigations was greatly in excess of that artificially injected in the enemata is that material from previous days was retained and expelled along with the stools passed on test days.)

Case 2.-Gastric ulcer. Man, aged 27.

Food: Peptonized milk and eggs.

NITROGENOUS BALANCE.-FIRST DAY.

Total intake of food nitrogen $\ldots \ldots \ldots \ldots \ldots \ldots \ldots \ldots .37$ grams.

Total nitrogen output (urine, 15.52 grams; feces, -; irrigation, 6.89 grams ) .........................

Total loss of nitrogen, 24 hours, output in excess of intake...16.04 grams. (Patient could not be weighed.)

NITROGENOUS BALANCE.-SECOND DAY.

Total intake of food nitrogen $\ldots \ldots \ldots \ldots \ldots \ldots \ldots \ldots .35$ grams.

Total nitrogen output (urine, 15.60 grams; feces, 9.06

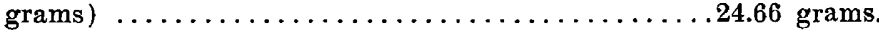

Total loss of nitrogen, 24 hours, output in excess of intake...18.31 grams.

CASE 3.-Postoperative perforating gastric ulcer. Man, aged 23.

Food formula, peptonized milk and egg, with panopeptone. Patient had been on this several days, when test was made only on one day, so that it is rather incomplete. Daily volume, 712 c.c.

Total intake of food nitrogen ............... 4.69 grams.

Total nitrogen output (urine, 19.04 grams; feces, 9.84 grams ) $\ldots \ldots \ldots \ldots \ldots \ldots \ldots \ldots \ldots \ldots \ldots \ldots \ldots \ldots \ldots \ldots \ldots$ grams.

Total loss of nitrogen, 24 hours, output in excess of intake.. .24.19 grams.

Little comment is needed in addition to a glance at the figures presented to prove the inadequacy of rectal feeding in these cases, and it may be assumed that in the vast majority of cases the results are little, if any, better.

The minus nitrogen balance varies from -8.81 grams to -24.19 grams, and is accompanied by a steady loss of weight in the first case (the only one weighed), apparently also in the others.

In a review of the literature on this subject, the only paper found to approach it from the standpoint of exact metabolism was by Edsall and Miller, ${ }^{4}$ who investigated two cases with rather better results, so far as

4. Wisconsin Med. Jour., 1903, i, 87. 
concerned actual absorption of the nutrient mixture of peptonized milk and eggs by the intestinal wall, but the nitrogenous loss averaged 11.8 to 70.9 grams nitrogen for the test period of six days. From clinical observation, however, and from the foregoing cases, the conclusion may be drawn with considerable certainty that rectal alimentation, as ordinarily practiced, is of little or no value in most instances, while in some it may prove harmful by using up the patient's strength. Of course, it has been proved that water is well absorbed by the rectum and that this method of introducing water is of extreme value.

Having satisfied ourselves of the foregoing facts, the next question which naturally arises is: Can nutritive equilibrium be maintained more satisfactorily by any other artificial means?

Many investigations have been undertaken to determine the effect of intravenous injections of various foodstuffs in solution. Although the prime object of most of such attempts has been to study the effects of these substances on the organism, incidentally side lights have been thrown on the subject of nutrition, although mostly in a negative way, as substances so injected have been proved unsuitable for use in artificial nutrition, either because of their toxicity or because they are immediately excreted for the most part.

Leaving out of consideration intraperitoneal nutrition as unsuitable and impracticable for continued use, one naturally turns to the problem of artificial nutrition by the hypodermic injections of foodstuffs. With the introduction of Chittenden's lowered food requirements it occurred to the writer to attempt to prepare an artificial, soluble food, containing the precise nutritive requirements for an individual calculated on Chittenden's figures; to inject it into the subcutaneous tissue and determine the nitrogen balance day by day, to see if the requirements of the body were being met, and the body maintained, not only in nitrogenous equilibrium, but also in weight.

The literature on this subject is surprisingly scanty. There are no articles accessible to the writer in which the subject has been approached from the standpoint of metabolism. What has been done may roughly be divided into clinical inquiries and laboratory experimentation. The clinical observations have been of the crudest sort, and the reports contain almost no data concerning the cases or, at best, very insufficient data. Whittaker, ${ }^{5}$ in $187 \%$, reported the case of a man nourished for six days by subcutaneous injections of milk, extract of beef and later cod liver oil; but from the article there is no proof that the man was nourished

5. Am. Jour. Med. Sc., April, 1877. 
in the real sense of the word, for no mention is made of body weight during this period, of the total amount of food injected, nor of the excretions, and we know that a patient can survive a short period of starvation with comparative ease. Kreng ${ }^{6}$ injected 15 to 20 c.c. of olive oil hypodermically for twenty days and succeeded in maintaining the patient's weight (?) and strength.

Pick $^{7}$ quotes a case from Whittaker, who nourished a girl suffering from gastric ulcer, with a weak pulse and high temperature, for four days by hypodermic injections of milk and beef-blood, with "great increase in weight and strength, after which period the patient was able to take nourishment by mouth and the temperature fell." The dose of milk was a dram at a time, which is an absurdly small amount relative to the nutritional requirements, and makes one extremely skeptical of the results as recorded.

Leube $^{8}$ injected a 20 per cent. sugar solution and found that it was well borne if only a few cubic centimeters were given at a time, but the limit of absorption was 15 to 20 grams of sugar in the twenty-four hours, all beyond this being excreted in the urine.

A more recent report by Barker ${ }^{9}$ speaks of the successful use of a 5 per cent. glucose solution in normal salt solution; this gives a solution which has the same freezing point as normal blood, $-0.56^{\circ} \mathrm{C} . \mathrm{He}$ used it in preparing some patients for operation, and only in one instance were the injections followed by glycosuria, although he fails to state the amounts injected, and gives no weights or metabolism data. This was tried on one case of marked asthenia from pyloric stenosis, but without success, as the patient died of exhaustion. On the other hand, most other experimenters agree that the usefulness of glucose is very slight, as it is so promptly excreted when given in nourishing amounts, while in the hands of some it has caused necrosis at the point of injection.

Turning to the purely experimental aspect of the subject, we find more data, but the results have been largely negative or unsatisfactory.

of the substances tried, fat, in the form of oil or butter, has been most frequently used. Without going into the details of the various experiments, we may take Henderson and Crofutt's ${ }^{10}$ statement as embodying the latest and most satisfactory results of experimentation along this line. They say: "Oil injected subcutaneously is readily and widely distributed through the subcutaneous tissue. It is not transformed in

6. New York Med. Jour., March, 1876.

\footnotetext{
7. Deutsch. med. Wchnschr., 1879, v, 31.

8. Verhandl. Cong. innere med., Wiesbaden, 1895, xiii, 418.

9. Am. Med., 1905, ix, 234.

10. Am. Jour. Physiol., I905, xiv, 193.
} 
situ into adipose tissue. The tissues react to its presence as to any nonirritating, foreign substance. In the blood and lymph it does not appear in detectable amounts, and, while the oil is ultimately absorbed and utilized in metabolism, the process is one of extreme slowness. Oil injections in any moderate amount are, therefore, practically without nutritive value."

Winternitz ${ }^{11}$ found that only 2 to 5 grams per day were utilized and that for subcutaneous nourishment it was not of practical value.

When we come to consider the availability of protein for subcutaneous injection, we are met by a variety of opinions. Eichorn, ${ }^{12}$ in a series of experiments, used cow's milk ( $1 / 3$ water), "Sanders peptone" and egg albumin. He concluded (1) that they are wholly absorbed, (2) that egg albumin often leads to abscess formation, (3) that cow's milk, diluted, takes the longest time for absorption, (4) that there is no local reaction from 20 grams of peptone. He also injected five dogs with albumin, olive oil, cod liver oil, almond oil and sugar solution, and states that most of the dogs maintained their weight. Few details of the experiments are given and there are absolutely no metabolism figures; the whole subject is very incompletely treated.

In another series of experiments, he used defibrinated pigs' blood and calves' blood, but without satisfactory results, and concluded his article by saying: "When we look at the results of subcutaneous injection of foods, we can assume that materials which do not inflame the cellular tissue when injected can be used for a while, often to advantage, to save life or postpone death by starvation."

Leube $^{13}$ found that the injection of 18 grams of "somatose" into a dog caused marked disturbance of well-being and led to albuminuria, due to renal irritation (see also results of somatose injections in these experiments).

Ewald, ${ }^{14}$ discussing the subject, dismisses with a word albumoses and peptones as poisonous and useless.

Leube, ${ }^{15}$ in a later article, speaks much in the same way, but suggests that possibly albumin, in the form of an alkali albuminate or syntonin, might be of use, although he had not tried it (see second experiment in this series).

11. Winternitz, Ztschr. f. klin. Med., 1903, 1, 80, 101.

12. Wien. klin. Wehnschr., 1881, 918.

13. Verhandl. Cong. innere Med., Wiesbaden, 1895, xiii, 418.

14. Cong. internat. de méd., xiii, Paris, 1900.

15. Ibid. 
Four years ago Trolldenier ${ }^{16}$ used an albuminous substance intermediate between the peptones and albumoses. Of this he gave 100 c.c. (10 per cent. solution) to each of several dogs. In summarizing his results he says that the dogs maintained their weight; that the urine showed albumose; that the injections were painful, and that abscesses developed at the point of injection. It is hard to believe that these dogs could possibly have kept their weight on the amount of protein which Trolldenier gave them, as it has been found that a dog needs at least 0.3 gram nitrogen per kilo to maintain nitrogenous equilibrium, while these dogs received but a fraction of that, about 0.2 gram.

From this brief review of some of the most important contributions to the subject, it can readily be seen that the problem of providing sufficient food to an animal by injection and at the same time approximately maintaining its nitrogenous equilibrium, to say nothing of its weight, is a most difficult one. It was felt, however, that it would be exceedingly desirable to attempt it, inasmuch as, if successful, some plan might be evolved for artificial nutrition in man, although any method to accomplish this successfully must be both clinically safe and nutritively sufficient, or nearly so, and must rest on the scientific facts of metabolism. Toward this end the following experiments were performed on dogs :

EXPERIMENTS ON DOGS.

Preparation of the Dogs.-As a routine, the dogs were put on the regular laboratory diet and confined in metabolism cages, where all excreta could be saved for analysis. As a rule, the dogs lost a little weight for a few days, and then settled down to almost constant weight from day to day. It was not until this had been accomplished that an experiment was attempted.

In the first attempt a food which was theoretically perfect was prepared from "somatose," representing the protein element in the form of soluble meat peptone, at the dog requirement of 0.3 gram nitrogen per kilo; the remaining requisite number of heat units (on human basis) being made up of glucose in normal salt solution, the whole being sterilized by thorough boiling.

Experiment 1.-Three preliminary injections were made of this food, the first representing 0.66 gram somatose per kilo, the other two 0.42 gram per kilo each, and the effects were noted. The larger amounts caused marked toxic symptoms, trembling, inability to stand, and rise of temperature, a trifle over $4^{\circ} \mathrm{F}$. within four hours. The smaller amounts were better borne, 'but still gave rise to some toxemia. The urine after the third injection gave a positive biuret reaction, and sugar was also present, but apparently in small amount. After a few days of rest on regular mouth-feeding, a forty-eight hour period was begun with the same food, dividing the twenty-four hour requirement into three injections for morning, afternoon and evening; at each injection an amount of peptone was used equal to 0.5 gram per kilo of weight.

Without going into the details of this experiment, it was seen that the dog showed less and less reaction, although the effects were too severe to constitute a result at all satisfactory from a clinical point of view. The temperature rose

16. Berl. klin. Wehnschr., 1903, xl, 912. 
from $2^{\circ}$ to $3^{\circ} \mathrm{F}$., and the dog became weak and ill, the urine was lessened in amount, contained albumin, peptone, sugar, hyaline and granular casts. The injection fluid collected on the under side of the body and caused marked edema. Between the $10 \mathrm{p}$. m. and the $10 \mathrm{a}$. m. feeding of the following day, the dog largely recovered its normal physical condition.

Following the period of injections, the dog passed an excessive amount of urine, probably from the subsidence of the edema, and continued losing some weight, even after it had been on regular mouth feeding again, receiving daily the same amount of food that had maintained it previously at a practically stationary weight. This loss in weight continued for a few days, then the weight remained stationary at a lower level. This, curiously enough, was the rule after most of the injection experiments. These results were not such as were thought worth following up as the toxemia was too marked, and for this reason chemical analyses were not made. Table 1 shows in graphic form the data collected.

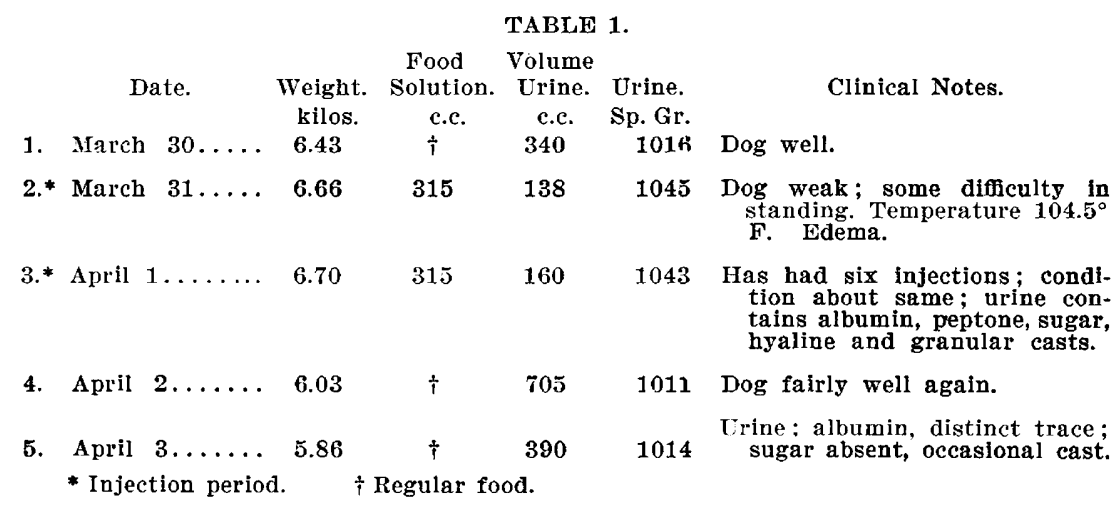

EXPERIMENT 2.-In the second experiment it was thought that possibly an alkali albuminate made from meat would meet the essential qualities of solubility and being capable of sterilization and mighc also be found to be less toxic than the peptone; this was prepared and diluted with normal salt solution. No account was taken in this experiment of furnishing the required calories, as it was undertaken solely with the view of seeing whether or not such a preparation would be of use.

The results of the injection of the alkali albuminate were most unsatisfactory, causing vomiting, bloody diarrhea, renal irritation, and local necrosis at points of injection.

The meat peptone and albuminate having proved so unsatisfactory, it was thought that possibly the peptone from cow's milk might be better borne, for it was conceivable that some of the toxicity of the meat peptone preparations might have been due to the extractives present.

In order to make this milk peptone, the certified city milk was used, after removing the gravity cream (as we have seen the fats are so slowly and insufficiently absorbed) ; this was then digested for three hours, by means of dry extract of pancreas with dilute sodium carbonate. The liquid was then sterilized by boiling, strained and put in sterile flasks after removing a sample for nitrogen determination.

EXPERIMENT 3.-For this experiment a small, pregnant dog, weighing 5.19 kilos, was used, and in order to find out at once the toxicity of this milk peptone, rather large amounts were used, equivalent to $0.4 \mathrm{gram}$ nitrogen per kilo, divided into two doses, given twelve hours apart. Following the first injection, the dog gave birth to one normal pup. There were only moderate toxic symptoms, nothing 
like as severe as those following becf peptone and albuminate. Although the results with the milk peptone were not entirely satisfactory, it was decided to go ahead, employing a three-day period with this large amount of protein injection. The reason for using so much more than the absolute dog requirement was to determine whether or not it was dangerously toxic, this pereentage of nitrogen per kilo being nearly four times that required for man.

In spite of this, it will be seen that the mother lost weight decidedly, and after the first day the temperature rose $2^{\circ} \mathrm{F}$. and remained up. Some milk was secreted, but the pup failed to get sufficient nourishment and lost weight steadily. At the end of the third day, the mother was only in fair condition, was considerably poisoned, as evidenced by temperature, malaise and suffusion of conjunctivæ. The pup had lost in weight and strength, so it was decided to stop the experiment and return the mother to regular mouth feeding. This was done at the end of the third day, and, although more milk began to be secreted, the pup was now too weak to get a supply, and died on the fifth day. After the first day, the mother refused all water by mouth, as she was evidently receiving sufficient fluid from the injections.

It will be seen on examining Table 2 from this case, that at the end of the first twenty-four hours, the amount of urine excreted was smaller than normal (the usual occurrence in these cases), but of very high specific gravity, 1076 the first day and 1052 the second. These figures were much higher than any obtained throughout the entire series of experiments, and although no exact metabolism experiments were made, as the case was of too short duration and the conditions too exceptional to make it of value, the rate of metabolism was evidently excessive and was unquestionably a great factor in the safety of the animal, for the next two dogs, in one instance on the same and in the other on a smaller amount of nitrogen per kilo, died of toxemia.

In trying to find a satisfactory explanation for this fact, viz., that this dog survived these injections, it was learned that Zachwegrwski ${ }^{17}$ proved that in pregnant women there was antepartum nitrogen retention, and that postpartum there was a decided nitrogen loss, equilibrium not being established for four or five days, or even Ionger. He believed that the involution of the uterus caused the high nitrogen output accompanied by excessive nitrogen metabolism. It would certainly seem that this was the case, as the animal lost flesh out of proportion to the other animals, although it was on a higher percentage of nitrogen. So far as the pup is concerned, the method of hypodermic feeding of the mother failed to furnish the requisite amount of food, but as this was a very severe test for an artificial form of feeding, it is not surprising that it failed to meet these unusual demands.

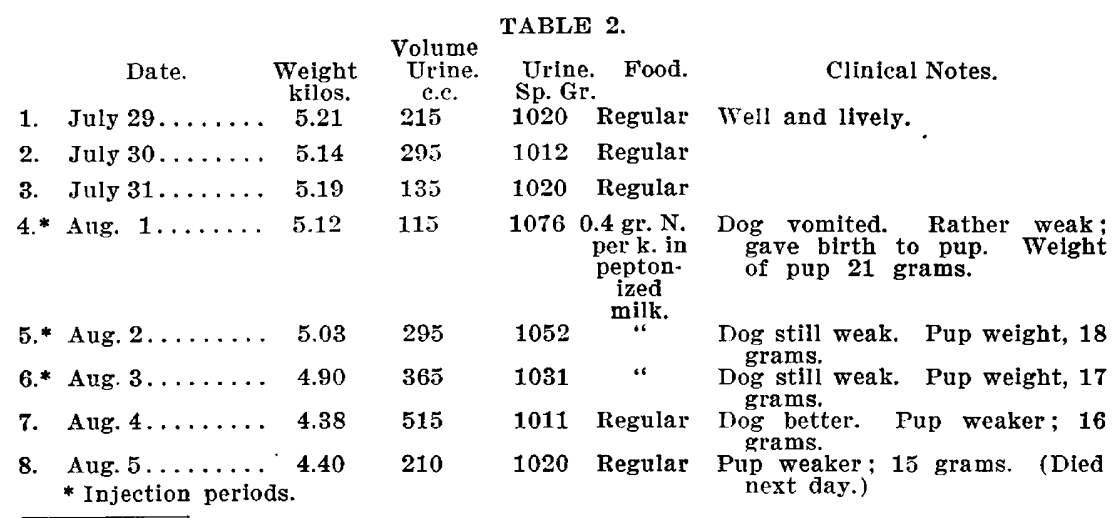

17. Ztschr. f. Biol., 1894, xxx, 405 . 
EXPERIMENT 4.--In order to see whether the peptonized milk would prove as toxic under what might be termed normal conditions, another dog was injected with the same amount of nitrogen per kilo, namely 0.4 gram, divided into two doses daily. After the first injection, the toxic symptoms of the peptone were very evident, for the dog looked sick and could not rise. It received only three injections, at twelve hour intervals, showing after each more and more evidence of toxemia and dying twelve hours after the third injection.

The autopsy showed marked subcutaneous edema on the flanks and under the belly; skin dark purple and ecchymotic. On section, this area of edema was found infiltrated with bloody, serous fluid. The organs were sent to the Cornell Pathologic Laboratory and the following report was received:

"Liver.-The whole section stains poorly. Many lobules show a marked degeneration as from a severe toxemia. The ability of the cell body and nucleus to take on basic stain has been lost, indicating changes in the direction of degeneration, if not necrosis. The vascular elements seem normal.

"Kidney.-Tubules were in a condition of eloudy swelling and granular degeneration. Glomeruli, interstitial tissue, blood vessels appear normal.

"Heart and Spleen.-Normal.

"Intestines.-Some congestion in spots; no hemorrhages."

EXPERIMENT 5.-The next trial to be recorded was with the peptonized skimmed milk, but peptonized only one hour and a half, as it was thought that possibly the length of the peptonization might make some difference in the degree of toxicity. Then instead of suddenly changing from all mouth feeding to all hypodermic feeding it was thought that it might be safer to make the change more gradually. The first day, three-quarters of the regular amount were given by mouth and onequarter by hypodermic injection. The next day half mouth feeding and half hypo. dermic injection were resorted to, always on the basis of 0.3 gram nitrogen per kilo.

These injections caused some toxemia from the first, but it was not until the second day that the dog looked really ill, and on the morning of the third day he was found dead, apparently from the same form of toxemia as killed the preced. ing dog. The first day's injection represented 0.075 gram of nitrogen per kilo; the second day's, 0.15 gram of nitrogen per kilo.

The autopsy revealed local edema with serous bloody fluid. The examination of liver and kidneys could not be completed in time, but on gross examination presented only slight evidences of cloudy swelling.

Although the outlook for accomplishing artificial nutrition with anything like exactness by the use of milk seemed most unpromising, it was felt that with milk as the most readily obtainable food, easy of preparation and sterilization, it would be worth giving it a final trial in the hope that some immunity to the poisonous effects might be acquired by using very small amounts at a time and increasing very gradually, waiting for all symptoms to subside before repeating the treatment.

EXPERIMENT 6. - The milk was skimmed and peptonized as in the last experiment, for one and a half hours, then sterilized. A 50 per cent. glucose solution was also prepared, in order to see how this would act in connection with the milk, thus furnishing some extra heat units.

A lively $\mathrm{dog}$ was obtained, put on the Iaboratory fare, weighed daily, and allowed to reach practically a stationary weight, which it did on a diet of 0.61 gram of nitrogen per kilo, although on this diet it put on 0.4 to 0.5 gram of nitrogen. A period of thirteen days was consumed in the experimental feeding, previous to which the dog, as has already been stated, was at an almost constant weight, although the nitrogen balance showed the 0.4 to 0.5 gram plus per day.

The injections were begun with very small amounts, e. g., 0.098 gram of nitrogen per kilo, divided into two injections, and, as a rule, the amount was not increased for forty-eight hours. Including the two aays on regular mouth feeding, 
preceding the experiment, and on all the thirteen days during which hypodermic nutrition was successfully maintained, the nitrogen balance was determiend daily. While this always showed a minus balance, $i$. e., the dog was excreting more nitrogen than it received in the food injected, still, with each increase in the amount of food the minus balance grew steadily less until on the tenth and eleventh days it was only 0.5 gram of nitrogen, the body weight remaining almost constant on those days. The food was then reduced and the munus nitrogen balance again increased to -2.62 gram. On increasing the food, it again sank to -0.311 gram on the fourteenth day.

These injections were given precisely as the others, twice daily, twelve hours apart, under aseptic precautions, and the animal showed surprisingly little reaction to them. During the earlier days of the injections, when the amount of nitrogen injected was low and the dog, of course, losing weight, he was not so lively, but was not ill; as the quantity of nitrogen was increased to 0.33 gram per kilo his general well-being improved and he was bright, lively and apparently normal. Up to the point of receiving 0.22 gram of nitrogen per kilo, there was no biuret reaction in the urine, showing that the peptone was being utilized completely. After this, there was always a slight reaction, increasing somewhat as the percentage of nitrogen was increased, although the dog's apparent well-being was improved and he seemed normal.

At times there was a trace of albumin in the urine, but never more; at no time were there casts. The sugar injected varied from nearly 4 grams per kilo per day to a little less than 1 gram, and varying amounts could always be detected in the urine. The lactose from the milk injections alone gave a moderate reduction of the copper, but not a quick, strong reaction, as when the glucose was injected. No accurate estimations of the amount of excreted sugar were made.

The dog's temperature at the beginning of the experiment was $103^{\circ} \mathrm{F}$. (somewhat above normal), and never rose over $103.2^{\circ} \mathrm{F}$. during the entire period of thirteen days. After the first two days, the dog was never thirsty and refused water during the last eleven days; it received more water by the injections than it really needed.

After the twenty-sixth (the last) injection on the thirteenth day of this experiment, the dog played about, ran to his eage wagging his tail, showing a very nearly normal physical condition, except for the moderate loss in weight, 0.85 kilo. The loss of weight, which set in late in the experiment, probably shows that such a purely artificial form of nutrition can not be maintained indefinitely (Table 3 ).

SUMMARY.

In offering a short review of these experiments, the results may be stated in a few words as follows:

1. By the ordinary method of rectal alimentation it is practically impossible to nourish patients properly or to maintain nitrogenous equilibrium. There are probably few, if any, exceptions to this rule.

2. The hypodermic use of meat peptones and alkali albuminates is not feasible for artificial nutrition on account of their great toxicity and tendency to cause local necrosis.

3. Skimmed milk, peptonized one and one-half to three hours, may prove fatal if given hypodermically.

4. It was found possible to furnish a dog with full nitrogenous requirements in the form of skimmed milk, peptonized one and one-half hours, and injected hypodermically in gradually increasing doses; when 


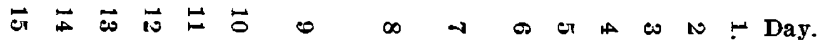

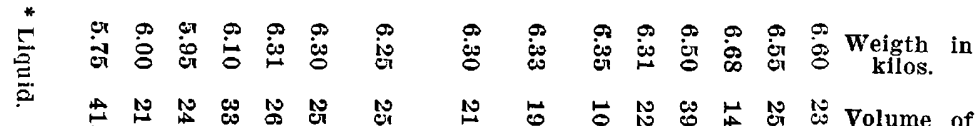

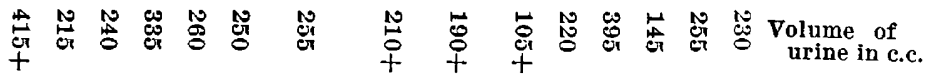

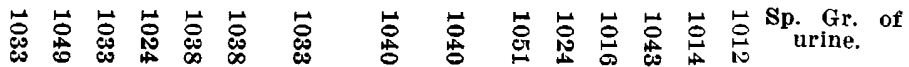

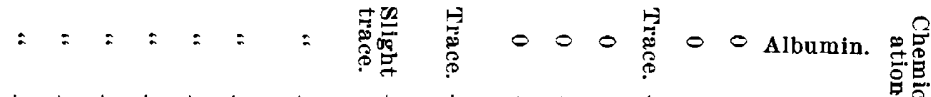

++++++++++++0 o Sugar.

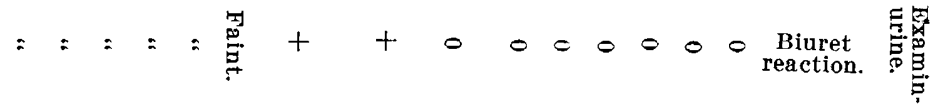

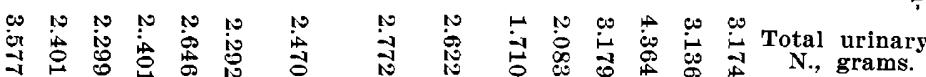

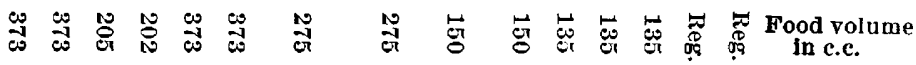

雨

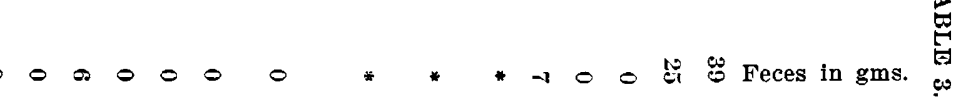

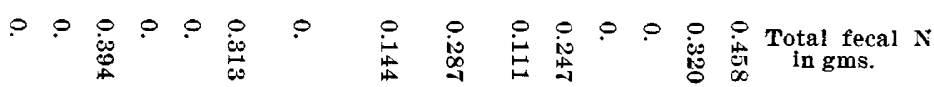

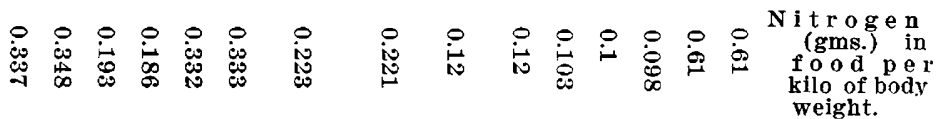

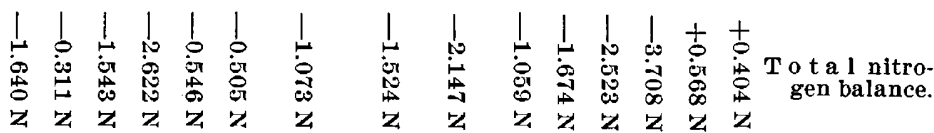

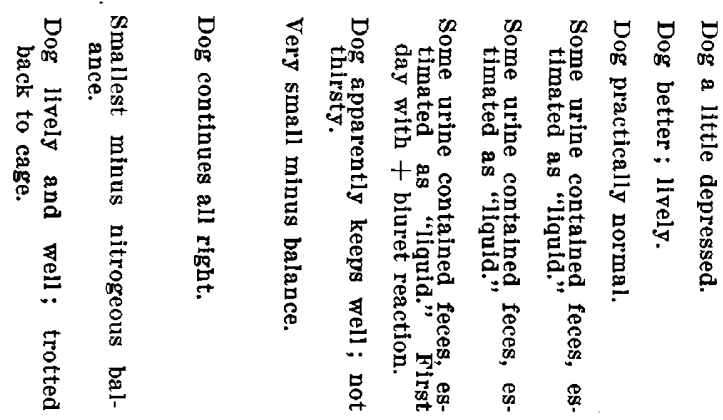

思 
on the larger amounts of food the weight remained almost stationary, the nitrogenous balance showed only 0.3 to 0.5 gram loss, the dog being apparently physically in good condition.

5. For ordinary use, although successfully carried out in this instance, milk peptone when injected hypodermically must be considered dangerous, and until some method for avoiding the greater part of the natural toxicity of the product can be found, should not be used for nutritive purposes in man.

Since nutrition may be thus artificially carried out in dogs, it does not seem improbable that some modification of the method may be found that would be suitable for man, particularly as the minimum human nitrogen requirements are, per kilo, less than one-half that of the dog.

Addenda.--A subsequent attempt was made to nourish a dog on milk to which extract of pancreas had been added at the time of injection in the hope that the process of peptonization would take place slowly in the tissues, thus reducing the tendency to toxic effects from large amounts of peptone. The experiment, however, was a failure, as the material caused wide local necrosis and made the dog exceedingly ill. It was then thought that possibly a dog might be immunized against this form of peptone, that serum from this animal might prove effectual in protecting another. The attempt was made, but, although the dog which it was attempted to immunize showed a lessening reaction to the poisonous effects of the peptone, it never became immune. This, it was found, coincided with the experience of Friedman and Isaacs. ${ }^{18}$

My hearty thanks are due to the attending and house staff of the Presbyterian Hospital for the clinical material and to Prof. Wm. T. Gies. of the Department of Biologic Chemistry of Columbia University at the College of Physicians and Surgeons, for many helpful suggestions and valuable advice in connection with the metabolism experiments as they were carried out under his supervision.

$66 \mathrm{~W}$. Fifty-fifth Street.

18. Zeitsch. f. Exp. Thera. Path., 1908. 